\title{
PREFACE OF THE FIRST ISSUE
}

Sixty years ago the University of Tartu published the first issue of the annual titled Skandinavskii sbornik [The Scandinavian Review], ${ }^{1}$ which for the next thirty-five years served as the main scholarly forum for the Soviet scholars of the Nordic studies. Its editors aimed to study the long-term historical processes in the communities and nations of Northern Europe, focusing mainly on the periods of peace, rather than on wars, arguing that peaceful coexistence is "the most natural relations among the nations" (Issue 1, page 5). The editorial board cooperated with the leading specialists in the archaeology, ethnography, history, economy, languages, literatures, and art of the Nordic countries from many Soviet universities, as well as from Scandinavia, Finland, Germany, and Poland. The contribution of The Scandinavian Review to the development of the Nordic studies in the USSR and its successor states is hard to overestimate. Unfortunately, the collapse of the Soviet Union marked the end of the annual. Its last XXXIIIth issue was published in $1990 .^{2}$

During the Soviet era, major schools of the Nordic studies emerged at the institutes of the Soviet Academy of Sciences and universities in such cities as Moscow, Leningrad, Tartu and Petrozavodsk.

Petrozavodsk has traditionally been a leading Russian centre of the Finnish studies as an interdisciplinary field combining research in language, culture, literature and history of Finland, as well as the Russian/Soviet-Finnish relations. The Finnish studies, in fact, influenced the very foundations of institutional scholarship in the Republic of Karelia beginning with the first publications on the history of Finland and Karelia (1920s and early 1930s), the establishment of the Karelian Research Institute in 1930, and the establishment of the Karelian-Finnish State University in 1940.

The Finnish studies in Karelia have undergone intense development in the past seventy years. To a large degree, it was due to a dedicated and systematic training of new specialists in this field. From its first years, the Petrozavodsk State University has offered a degree in the Finnish language, and in the 1970s a new program was opened in the history of the Scandinavian countries, Finland, and the Russian-Finnish relations.

In 2012, the Petrozavodsk State University established the Interdisciplinary Scientific and Educational Centre of the Baltic and Finnish Research "FENNICA." It serves as a modern scholarly, expert, and analytical venue providing a higher level of research and education for

\footnotetext{
${ }^{1}$ Vil'iam V. Pokhliobkin and Lidiia K. Roots (eds), Skandinavskii sbornik 1, (Tallinn: The Estonian State Press, 1956), $265 \mathrm{p}$.

${ }^{2}$ See a bibliography of the materials published in The Scandinavian Review at http://ulfdalir.ru/ukazatel.
} 
Russian specialists in the history of Finland, the Baltic and Finnish languages, literatures and cultures, Russian-Finnish relations, and cross-cultural communication. Its experience and expertise helped to establish in 2016 a similar centre with a broader scope of the Nordic studies in general - the Interdisciplinary Scientific and Educational Centre "NORDICA" at the Institute of Language, Literature and History of the Karelian Research Centre of the Russian Academy of Sciences.

In order to facilitate the activities of the both centres, to coordinate the research of Russian specialists in the Nordic studies, and to increase international cooperation in this field we decided to launch a new international scholarly peer-reviewed annual - The Nordic and Baltic Studies Review. We believe that it can revive the best traditions of The Scandinavian Review.

We expect the journal to serve as an international scholarly online forum that should reflect the current state and define the research perspectives in the Nordic studies and education. As an interdisciplinary forum, the journal seeks to support and advance the efforts of scholars from different countries in the fields of history, international relations, political science, cultures, literatures, and languages of the Nordic countries and the Baltic Sea region.

The journal is particularly interested to cover the themes of interrelatedness, mutual influences, and trans-border contacts in the Nordic countries and the Baltic Sea region from the Viking Age to the present day. The journal welcomes special issues, which can include proceedings of relevant conferences or address a specific theme.

The electronic format of the journal provides an opportunity to publish longer texts which is often impossible with traditional print journals. In addition, our plans include the publication of primary sources, as well as descriptions of archival collections and bibliographies. These materials have their audience, but are only occasionally published in print journals.

The first issue includes, in addition to scholarly papers and reviews, a large analytical review of the archival collection on the Shueretskaia volost (region) during the Great Northern War of $1700-21$, which is stored in the Archive of the Karelian Research Centre of the Russian Academy of Sciences.

The editorial board is open for collaboration with interested parties. We expect that through our joint effort The Nordic and Baltic Studies Review will become an important contribution to the advancement of the Nordic studies in Russia.

Irina Takala 